\title{
Connecting with Millennials: Using tag clouds to build a folksonomy from key Home Economics documents
}

\author{
Donna Pendergast \\ Griffith University
}

\begin{abstract}
Coinciding with the celebration of the centennial of the International Federation for Home Economics (IFHE) in 2008 and the American Association for Family and Consumer Sciences (AAFCS) in 2009, several celebratory events have taken place and a number of artefacts produced. These serve as a permanent legacy and historical account of the attainment of the centennial. In this study, selected artefacts are analysed and re/presented using a contemporary tool that connects specifically with the multi-literacy capabilities of the emerging generation in schools, tertiary institutions and new entrants in the workforce - the Millennials - who are the future generation of home economists. Through the use of tag clouds evidence of the emergence of a folksonomy of terms associated with the field is apparent, featuring words such as: profession, social, life, future.
\end{abstract}

\section{Context}

\section{One hundred years}

In 2008 the International Federation for Home Economics (IFHE) celebrated its centennial year at the World Congress in Switzerland. This milestone event was held in the same part of the world the original visionaries responsible for establishing the organisation met and formalised the network at an invitational congress. In the year following the founding of IFHE, the American Home Economics Association (AHEA) was established. One hundred years later it is known as the American Association for Family and Consumer Sciences (AAFCS).

Coinciding with the 100 year celebrations, IFHE launched a number of important initiatives:

1. A book recounting the history of the federation: Arcus, M. (2008). 100 Years of the International Federation for Home Economics 1908-2008. Bonn: IFHE.

2. An e-book: Global Sustainable Development: A Challenge for Consumer Citizens

3. An edited book compiling the Congress proceedings: Pendergast, D. (Ed.) (2008). Home Economics: Reflecting the Past; Creating the Future. Proceedings of the IFHE XXI World Congress, July 26-31, Switzerland. Bonn: IFHE.

4. A DVD also recounting the 100 year history of the profession: The International Federation for Home Economics 100 years 1908-2009

5. A position statement for the profession: IFHE Position Statement - Home Economics in the $21^{\text {st }}$ Century, available in print and electronically 
The World Congress with the title Home Economics: Reflecting the Past; Creating the future, was structured with sessions to celebrate the $100^{\text {th }}$ anniversary of the establishment of the International Federation of Home Economics (IFHE) and to look ahead to the future years of the professional body and the field of study it represents. The title of the conference and the subsequent thematic directions served to focus home economists and allied professionals on the questions of sustainability, advocacy and the active creation of preferred futures for home economics, relevant disciplinary fields, and the profession itself, while critically reflecting upon and being informed by its historical roots. The futures-related challenges explored at the conference included: changing global demographic patterns; future orientated education; the pillars of sustainability; consumers and consumption patterns; under- and over- nutrition; Information and Communication Technologies (ICT's) and the interplay and effects with family and individual wellbeing; changing generational patterns that impact on the home economics profession and the need to better understand and utilise these traits as a basis for future directions for the profession. Proceedings of the Congress were published as an edited book (Pendergast, 2008a).

In 2009 the American Association for Family and Consumer Sciences has similarly celebrated with the 100th Annual Conference \& Expo themed Celebrating the Past, Sustaining the Future. The conference provided the opportunity to work on solutions to current sustainability issues, such as designing more eco-friendly fabrics, reducing waste in food preparation, and increasing the use of recycling in homes, schools, and workplaces. To commemorate AAFCS' Centennial, the conference addressed the history and future of the Association and the Family and Consumer Sciences profession. AAFCS have also produced a DVD about the founder and architect of the organization, Ellen Swallow Richards, titled The Life and Legacy of Ellen Swallow Richards.

The conferences and their associated artefacts - books, DVD's, Position Statements and the like - are tangible products that serve as a permanent legacy and historical account of the attainment of the centennial, and for that reason are potential sites for research and analysis. Of interest in this study is analysing selected artefacts using a contemporary methodology that connects specifically with the unique traits of the emerging generation in schools and tertiary institutions - the Millennials - who are the future generation of home economists (Pendergast, 2006).

\section{Home Economics in digital times - the Millennials}

Much has changed in the one hundred years since the inception of IFHE and AAFC. The capacity for relatively easy, fast, convenient and inexpensive travel and for same-time communication is a vast contrast to the challenges of networking professionally one hundred years ago. As noted by Arcus (2008, p.4) in reference to the first IFHE congress in 1908 "despite the difficulties of travel and communication and the lack of an established network for contacting home economists in different countries, the congress attracted 750 participants”, including participants from the United States of America.

One hundred years later, we belong to the information era, also known as the networked and the digital age. This is a time when the production and dissemination of information 
dominates our lives and lifestyle. The widespread range, capability and availability of information networks such as the World Wide Web, mobile phone technologies and digital applications makes Information and Communication Technology (ICT) a defining aspect of contemporary times. Globalisation, which is closely bound with ICT's is another defining feature (Pinquart \& Silbereisen, 2005), making the exchange of information via digital means quick and relatively uncensored, compared to the book based culture of one hundred years ago. The capacity for virtual networking and information sharing is beyond the possible imagination of the first delegates at the founding conferences in 1908 and 1909.

Globalisation is regarded broadly as any range of processes, innovations and changes that increase the interconnectedness of the world. Globalisation of the economy is bound to the expansion of new communications technologies, such as the internet, creating a global village where the traditional boundaries of time and geographic space have been negated. Consequently, the current era is one of unprecedented transition from industrial to information-based culture and economy, from print based to multi-mediated, digital approaches to communication. This is a significant paradigm shift, in fact it is well documented that this is the most significant shift in human history (Pendergast, 2007). Electronic media has created a simultaneous universe, where constraints imposed previously by time and place, around which communities were established, have been penetrated. The ongoing and rapid metamorphoses and hybridisation of new media and the effects of media globalisation seem unfathomable.

From an educational perspective, the shift in communications technologies has changed the way literacy is now understood, taking it from the one dimensional concept of literacy to the multi-layered conception of multi-literacies, as captured in the following quotation:

$[\mathrm{H}]$ istorically, communications media have included spoken language, writing, print and some visual media like photograph and film. Since World War II, the various electronic media such as television and other digital information technologies have provided much more complex audiovisual layers to these. ...Communications media require mastery of symbolic codes ranging from number systems to sign language, from linguistic grammars to computer codes. Networked societies call for various kinds of literacy simultaneously, the mastery of many different codes, and the capacity to switch between and blend multiliteracies (Education Queensland, 2009, np).

The generations born into the information age see this multi-modal diversity as normal (Henderson, 2008). Prensky (2005/6) terms those born into the information era 'digital natives' - persons born since 1985. Everyone alive today whose birth precedes the introduction of digital technologies (pre-1985) are known as digital immigrants. Digital natives are characterised as: operating at twitch speed (not conventional speed); employing random access (not step-by-step); parallel processing (not linear processing); graphics first (not text); play oriented (not work); connected (not stand alone). Hence, the twenty-first century has demanded a redefinition of the way information is received and processed, and it is important that as a profession we have the foresight to utilize the capacities of the digital age to enhance understanding and value of its potential role. As Henderson (2008, p. 14) notes, "the recognition of new literacy practices also requires an 
acknowledgement that new codes and conventions are in operation". Rennie and Patterson (2008, p.53-54) confirm this view, explaining that "reading is being reshaped by new forms of texts and round-the-clock access to information. The shift from physical texts (books, magazines, newspapers) to virtual texts is shaping a new type of reader". They note the emergence of a 'click and scan' generation, where screen reading is characterized by browsing text rather than detailed reading.

This means the currently emerging generation of home economics professionals are digital natives, and they respond to graphics and visuals before they respond to text. They have extensive multi-modal textual experience and are likely to have habitually established reading patterns associated with digital text browsing. They are multiliterate, not just literate. Digital natives align with the generation known as the YGeneration, or MilGen (Millennial Generation contraction) and these are the generational cohort that must be attracted and retained for the profession to survive and thrive in the future (Pendergast, 2009). The Millennial generation covers the birth years $1982-2002$ and in 2009 this is an age range of seven to twenty-seven years old (Pendergast, 2007). Pendergast argues that to retain this generation, the profession must "utilise the latest available communications technologies” (Pendergast, 2008b).

It is in this context that this study is located. Of interest is an investigation of some of the texts produced as artefacts of the centennial celebrations, viewed from a digital native perspective. One of the most recent of these tools is creating tag clouds to represent word content through information retrieval and visualisation, of the texts. This aspect will now be explored.

\section{Tag clouds}

Tag clouds are visualisations of term frequencies. A tag cloud presents common terms in a text by grouping like terms together and emphasizing frequent terms. According to Salonen (2007), tagging is the "new approach" (p.188) of "attaching tags to resources" (p.189), where resources are often "digital information objects, such as webpages, photos or video clips” (p.189). Tag clouds are typically visual representations of the word content of a resource in which attributes of the text such as size, font style or colour can be used to represent and classify features, including the frequency of the associated terms (Halvey \& Keane, 2007). For instance, a tag cloud might be constructed to present a term with font size 46 as representing the actual number of times it appears, and proportionately it might be twice as frequently occurring as a word presented in font size 23. The various relationships between actual frequency and font size, style and colour is virtually unlimited, and is part of the uniqueness of each tag cloud. Tag clouds commonly occur as features of websites, enabling readers to scan the relational values presented to determine if the site content is of relevance and interest. This is the aspect of tag clouds of interest in this study. If tag clouds can be used to determine relational values, then tag clouds can be used as a visual means to present content information, and to appeal to readers who respond best to a multiliteracy approach.

The use of tag clouds enables information retrieval and visualisation concurrently and simultaneously serves as a hierarchy. And as Salonen (2007, p.188) notes, "ideally this would mean that not only current relationships could be better understood, but also 
discovery of hidden properties of the data could be enabled". The use of tag clouds derived from a resource allows for that source to be analysed in terms of content through information retrieval, and visualised to present the relationships between the terms retrieved, thereby presenting a visual representation of the resource. This is an attractive way of presenting information to digital natives, and of providing concise summaries of key messages in a way that appeals and is familiar to an ICT literate reader. Indeed, tag clouds are frequently used on websites including business, personal, and social networking sites such as Facebook to present a snapshot image of the contents of the site, thereby attracting others to engage at greater depth if the tag clouds appeal to them.

Tagging contributes to the development of a folksonomy, which is a vocabulary of tags emerging from the content being analysed. Thomas Vander Wal coined the phrase 'folksonomy' as a means of categorizing what is appearing on the internet in particular (Pink, 2005). It is called 'folksonomy' to represent its meaning as a people's taxonomy. By identifying the common words used in a text and tagging them in a tag cloud, the development of a hierarchy or folksonomy occurs. In this way, a classification of the contents is possible.

Despite the increasing popularity of tag clouds, there have been very few studies evaluating their effectiveness in terms of accuracy of understanding by the viewer of the intended depiction. Some initial work conducted by Halvey and Keane (2007) does however provide some direction on what makes tag clouds most accurately comprehended, these being:

- alphabetization can aid users to find information more easily and quickly

- font size is very important for how quickly and easily users find information, with larger font size recommended

- position of tags is also very important (horizontal preferred); and

- users scan lists and clouds rather than read them.

With this knowledge in mind and given the availability and proliferation of ICT's, it is of interest to analyse the word content of the artefacts produced as historical record to celebrate the centennial, and to explore presenting this analysis in a form which connects with the MilGen - a visual textual form. By presenting the analysis as tag clouds, consideration of key messages being presented to the Millennial generation is possible. Of particular interest in this study is an analysis of the IFHE Position Statement and the IFHE Congress Proceedings, which serve as the historical account of the event and have been constructed to lead the profession into the future.

The study has the following objectives:

1. utilise tag cloud methodology to conduct an objective word content frequency analysis of selected resources;

2. depict the frequency using tag clouds; and

3. consider the development of folksonomy and what implications this has for the field of home economics and the connection to the millennial generation. 


\section{Method}

\section{Producing tag clouds}

This study utilised a very recent ICT tool, tag clouds, as the method of text analysis and of representation of the word content of selected documents. In order to prepare the text for tag cloud production, the following occurred:

1. References, flysheets, contents pages were removed

2. Common jargon phrases were found and replaced without a space, so as to differentiate them from other usages eg:

a. home economics became homeeconomics,

b. lifelong learning became lifelonglearning,

c. well being became wellbeing

d. home economist(s) became homeeconomist(s),

e. $21^{\text {st }}$ Century became 21stCentury.

3. The number of words was totalled using word counting software: Word Counter

4. Words that had similar meanings were combined to reflect the number of times that idea was used. Base words (lemmas) were identified and used rather than individual inflectional word-forms; for example: professions, professional, professionalism, are counted as examples of the lemma profession. In this way. overrepresentation of related concepts was eliminated.

5. The top terms and lemmas were compared against the Oxford collection of top 100 function word lemmas to see if the rankings were similar. Many of the most frequently used words are short function words whose main purpose is to join other, longer words rather than determine the meaning of a sentence. If these words are left in the text then they are likely to appear as the main elements of the tag cloud. The tag cloud therefore would reflect function words rather than content words.

6. The 100 most frequently used function words were removed from the text. These words were taken from the billion-word Oxford English Corpus (Oxford University Press, 2009).

7. The next 100 words were placed alphabetically in a tag cloud, with $1 / 10$ frequency of the word used as the font size.

Tag clouds were used in this study to determine the frequency of content words used in the selected texts. In addition to the seven step process detailed above, the creation of the tag clouds was guided by the principles noted previously, alphabetical order, large font size, and horizontal text. These frequency generated tags were then considered in terms of their potential contribution to the development of folksonomy.

\section{Documents selected for tag cloud production}

Two of the artefacts were selected for analysis. This was based on ease of access to the digital format of the texts and the importance of the documents both to the profession and to the millennial generation audience.

IFHE Position Statement - Home Economics in the $21^{\text {st }}$ Century 
The position statement is a two page document produced through a collaborative process with members of IFHE and more widely of the Home Economics profession (see Pendergast, 2008c). It is an attempt to locate the profession in the contemporary context by serving as a platform, looking ahead to viable and progressive visions of Home Economics for the twenty-first century and beyond. It is expected to be used to provide defensible arguments for individuals and professional groups requiring such support and is the product of extensive global consultation with members of IFHE and the home economics profession. The Statement is available from www.ifhe.org

\section{IFHE Congress Proceedings}

Pendergast, D. (Ed.) (2008). Home Economics: Reflecting the Past; Creating the Future. Proceedings of the IFHE XXI World Congress, July 26-31, Switzerland. Bonn: IFHE.

The congress proceeding is 178 pages long and includes all welcome statements, closing statements, along with two keynote addresses and eight plenary papers. The proceedings were distributed to all 1200 + delegates attending the congress.

\section{Results}

The tag clouds were produced for the two selected texts.

\section{IFHE Position Statement - Home Economics in the $21^{\text {st }}$ Century}

The following tag cloud was produced after the analysis steps were followed. For this tag cloud the top 88 terms were selected after functional lemmas were removed rather than the top 100 as a long list of words with frequency of 2 was produced. 
Figure 1 Tag Cloud of the IFHE Position Statement. Top 88 words after removing functional lemmas. Presented where Font size $=$ frequency $\times 2$

21stcentury achieve action advocate anead area basis both capacity challenges commit COMmunities concern

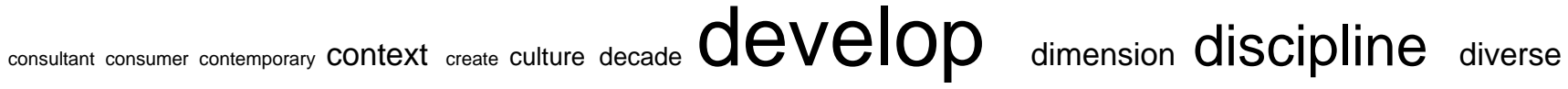

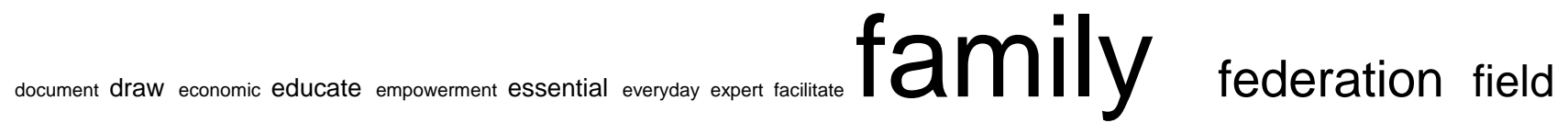

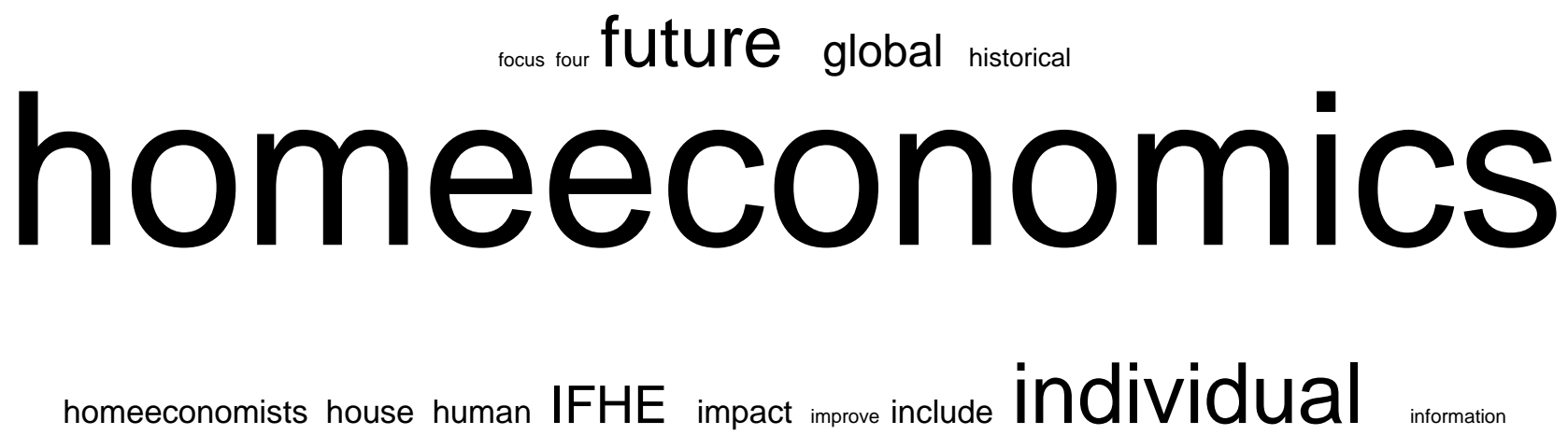

international issue learning levels life members multiple name need organisation political position potential practice profession proofing reflect relevant requirement schools science Serve situate SOCial specific statement strong study such sustain world 
The same data is presented in tabular form in Table 1 below. This form of data presentation is how this data might typically be presented. This highlights the limitations tabular presentation have compared to tag clouds, and vice versa.

Table 1 Word frequency in IFHE Position Statement.

\begin{tabular}{|c|c|c|c|}
\hline Word & Frequency & Word & Frequency \\
\hline 1. homeeconomics & 33 & 45. historical & 4 \\
\hline 2. $\quad$ profession & 28 & 46. name & 4 \\
\hline 3. family & 18 & 47. organisation & 4 \\
\hline 4. develop & 13 & 48. position & 4 \\
\hline 5. individual & 13 & 49. proofing & 4 \\
\hline 6. $\quad$ social & 13 & 50. statement & 4 \\
\hline 7. life & 12 & 51. strong & 4 \\
\hline 8. $\quad$ future & 11 & 52. such & 4 \\
\hline 9. communities & 9 & 53. ahead & 3 \\
\hline 10. discipline & 9 & 54. both & 3 \\
\hline 11. federation & 8 & 55. commit & 3 \\
\hline 12. ifhe & 8 & 56. concern & 3 \\
\hline 13. study & 8 & 57. consultant & 3 \\
\hline 14. sustain & 8 & 58. consumer & 3 \\
\hline 15. world & 8 & 59. contemporary & 3 \\
\hline 16. field & 7 & 60. create & 3 \\
\hline 17. global & 7 & 61. document & 3 \\
\hline 18. international & 7 & 62. economic & 3 \\
\hline 19. 21stcentury & 6 & 63. empowerment & 3 \\
\hline 20. action & 6 & 64. everyday & 3 \\
\hline 21. context & 6 & 65. expert & 3 \\
\hline 22. dimension & 6 & 66. facilitate & 3 \\
\hline 23. homeeconomists & 6 & 67. focus & 3 \\
\hline 24. house & 6 & 68. four & 3 \\
\hline 25. issue & 6 & 69. improve & 3 \\
\hline 26. learning & 6 & 70. information & 3 \\
\hline 27. advocate & 5 & 71. members & 3 \\
\hline 28. challenges & 5 & 72. multiple & 3 \\
\hline 29. diverse & 5 & 73. need & 3 \\
\hline 30. human & 5 & 74. political & 3 \\
\hline 31. impact & 5 & 75. potential & 3 \\
\hline 32. include & 5 & 76. reflect & 3 \\
\hline 33. levels & 5 & 77. relevant & 3 \\
\hline 34. practice & 5 & 78. requirement & 3 \\
\hline 35. serve & 5 & 79. schools & 3 \\
\hline 36. achieve & 4 & 80. science & 3 \\
\hline 37. area & 4 & 81. situate & 3 \\
\hline 38. basis & 4 & 82. specific & 3 \\
\hline 39. capacity & 4 & 83. technology & 3 \\
\hline 40. culture & 4 & 84. transformative & 3 \\
\hline 41. decade & 4 & 85. upon & 3 \\
\hline 42. draw & 4 & 86. various & 3 \\
\hline 43. educate & 4 & 87. vision & 3 \\
\hline 44. essential & 4 & 88. ways & 3 \\
\hline
\end{tabular}

\section{IFHE Congress Proceedings}

The following tag cloud was produced after the analysis steps were followed. For this tag cloud the top 100 terms were selected after functional lemmas were removed. 
Figure 2 Tag Cloud of the IFHE Congress Proceedings. Top 100 words after removing functional lemmas. Presented where Font size $=($ frequency/ 10$)$ rounded to nearest integer

able act base become best between challenge change child commitment community congress cOnSUme ${ }_{\text {continue }}$ contribute country create ${ }_{\text {critical }}$ culture $\mathrm{develOp}$ differ economy educate empower environment family federate field sous food ionfuture generat/ion global oow grow health nelp high history nome

\section{homeeconomics}

human idea identity $_{\text {hHE }}$ issue lead learn level Ife mean member nature need organise own population power practice problem process produce resource role science self serve should $\mathbf{S O C I} \mathbf{a l}$ strong student such sustain system teach technology those through understand value vary where within women WOrld

The same data is presented in tabular form in Table 2 below. This form of data presentation is how this data might typically be presented. Again, this highlights the limitations tabular presentation have compared to tag clouds, and vice versa. 
Table 2 Word frequency for IFHE Congress Proceedings.

\begin{tabular}{|c|c|c|c|}
\hline Word & Frequency & Word & Frequency \\
\hline 1. profession & 507 & 51. grow & 95 \\
\hline 2. homeeconomics & 413 & 52. learn & 93 \\
\hline 3. social & 311 & 53. understand & 91 \\
\hline 4. food & 302 & 54. culture & 89 \\
\hline 5. life & 275 & 55. mean & 89 \\
\hline 6. ifhe & 274 & 56. resource & 87 \\
\hline 7. generat/ion & 268 & 57. student & 87 \\
\hline 8. $\quad$ educate & 255 & 58. child & 86 \\
\hline 9. future & 247 & 59. homeeconomist & 85 \\
\hline 10. world & 245 & 60. level & 84 \\
\hline 11. develop & 242 & 61. reflect & 84 \\
\hline 12. family & 213 & 62. federate & 83 \\
\hline 13. consume & 209 & 63. women & 83 \\
\hline 14. need & 199 & 64. important & 82 \\
\hline 15. act & 193 & 65. self & 82 \\
\hline 16. practice & 189 & 66. house & 78 \\
\hline 17. history & 185 & 67. population & 78 \\
\hline 18. change & 183 & 68. include & 77 \\
\hline 19. member & 177 & 69. those & 76 \\
\hline 20. global & 160 & 70. contribute & 75 \\
\hline 21. empower & 146 & 71. high & 75 \\
\hline 22. lead & 145 & 72. issue & 74 \\
\hline 23. sustain & 143 & 73. through & 74 \\
\hline 24. individual & 137 & 74. between & 73 \\
\hline 25. produce & 134 & 75. process & 73 \\
\hline 26. economy & 133 & 76. great & 72 \\
\hline 27. international & 132 & 77. strong & 72 \\
\hline 28. human & 129 & 78. help & 71 \\
\hline 29. value & 129 & 79. teach & 71 \\
\hline 30. should & 128 & 80. environment & 70 \\
\hline 31. create & 127 & 81. become & 69 \\
\hline 32. commitment & 124 & 82. best & 69 \\
\hline 33. system & 124 & 83. field & 69 \\
\hline 34. technology & 121 & 84. home & 69 \\
\hline 35. community & 117 & 85. identity & 69 \\
\hline 36. country & 114 & 86. own & 69 \\
\hline 37. provide & 114 & 87. where & 69 \\
\hline 38. research & 112 & 88. able & 68 \\
\hline 39. base & 108 & 89. focus & 68 \\
\hline 40. increase & 106 & 90. within & 67 \\
\hline 41. serve & 104 & 91. vary & 66 \\
\hline 42. differ & 102 & 92. form & 65 \\
\hline 43. power & 102 & 93. role & 65 \\
\hline 44. science & 99 & 94. continue & 63 \\
\hline 45. health & 98 & 95. critical & 63 \\
\hline 46. organise & 98 & 96. idea & 63 \\
\hline
\end{tabular}




\begin{tabular}{|c|c|c|c|}
\hline Word & Frequency & Word & Frequency \\
\hline 47. such & 98 & 97. nature & 63 \\
\hline 48. congress & 97 & 98. problem & 63 \\
\hline 49. relate & 97 & 99. region & 63 \\
\hline 50. challenge & 95 & 100. must & 62 \\
\hline
\end{tabular}

An additional Tag Cloud analysis was conducted on the IFHE Congress Proceedings because of the presence of the term 'women' in the top 100 terms. In fact this term was the $63^{\text {rd }}$ most frequently used term (after functional lemmas removed). The following tag cloud was produced after the analysis steps were followed. For this tag cloud all gender specific terms were selected after functional lemmas were removed.

Figure 3 Tag Cloud of the IFHE Congress Proceedings Gender terms.

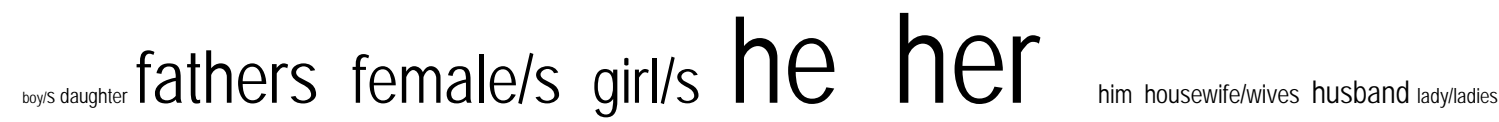

male/s man

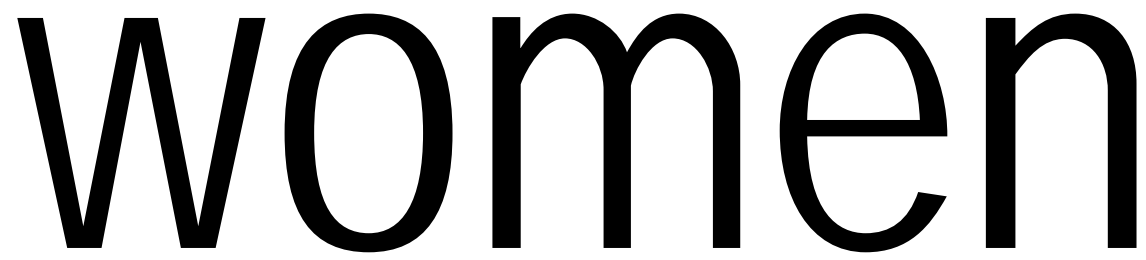

A detailed analysis of the frequency of gender specific terms is presented in Table 3 below. 
Table 3 Word frequency of gender specific terms in the IFHE Congress Proceedings

\begin{tabular}{|l|l|l|l|}
\hline Male & Female \\
\hline Boy(s) & 3 & Girl(s) & 12 \\
\hline Male(s) & 11 & Female(s) & 13 \\
\hline Man & 9 & Woman & 6 \\
\hline Men & 35 & Women & 83 \\
\hline Husband & 3 & Wife & 2 \\
\hline Son & 2 & Daughter & 2 \\
\hline & & Housewife/wives & 5 \\
\hline & & Lady/ladies & 4 \\
\hline fathers & 14 & mother/s & 18 \\
\hline he & 23 & she & 22 \\
\hline him & 5 & her & 24 \\
\hline Total & $\mathbf{1 0 5}$ & Total & $\mathbf{1 9 1}$ \\
\hline
\end{tabular}

\section{Discussion}

Millennials, as digital natives, have developed a wide repertoire of literacies. Until now there has been little imperative to consider alternative ways to analyse and re/present the messages that are communicated in extended text documents, as the audience for which they have typically been intended were digital immigrants or indeed analogue in their literacy capabilities. This means they favor certain ways of communicating and seeking meaning. However, this is changing as the Millennial generation have begun entering the home economics field of study as students in schools and as some of the newest members of the paid and unpaid workforce. With their multi-literate capabilities and a preference for visual rather than text, scanning for meaning and other characteristic comprehension styles, there is an incentive to ensure that the artifacts of the profession have meaning and usefulness for all generations, and are available in appealing and familiar formats for each generation.

By utilizing tag clouds to provide a visual hierarchy of the text, a snapshot that has clear synergies with the capabilities of digital natives has been produced. These tags provide an easily accessible content analysis which is instantly able to be interpreted. Also presented in the results is a detailed breakdown in tabular form of the actual frequencies and rankings of the individual words. The inclusion of the two formats demonstrate the benefits and limitations of both modes of presentation.

A high degree of alignment of the terms used in the IFHE Position Statement and the IFHE Congress Proceedings is evident, with five words: home economics $\left(1^{\text {st }}\right.$ and $2^{\text {nd }}$ respectively); profession $\left(2^{\text {nd }}\right.$ and $\left.1^{\text {st }}\right)$; social $\left(6^{\text {th }}\right.$ and $\left.3^{\text {rd }}\right)$; life $\left(7^{\text {th }}\right.$ and $\left.5^{\text {th }}\right)$; future $\left(8^{\text {th }}\right.$ and $9^{\text {th }}$ ) appearing in the top 10 list for both analyses. These five words dominate in the visual impression presented in the tag clouds (represented by proportional font size), 
which means they are used abundantly in the texts, suggesting a consistent emphasis on these terms in these artefacts.

The term 'family' is also high impact in the tag clouds, and is the third most frequent and twelfth most frequent term in the Position Statement and Congress Proceedings respectively. Other terms associated with the profession's connection with people stand out in the tag clouds, in particular the words 'social' (6th and 3rd respectively) and 'individual' ( $5^{\text {th }}$ and $24^{\text {th }}$ ). Interestingly, the word 'food' is strongly featured in the IFHE Congress Proceedings tag cloud, appearing in large font as it is the fourth most frequently used term. However, it does not feature in the tag cloud for the IFHE Position Statement. This might be explained by the difference in the purpose of the documents analysed, with the IFHE Position Statement providing a broad, comprehensive coverage of the range of fields in the profession, while the IFHE Congress Proceedings included focussed, context specific aspects.

The presence of action words is worth comment, along with the relative size of the words in the tag clouds, which conveys the impression of a profession which has a proactive commitment. The font size is large, suggesting high frequency of inclusion. This is evident in both the Position Statement and the Congress Proceeding tag clouds. For instance, the following words feature on either or both clouds: achieve, act, action, advocate, challenge, change, consume, develop, educate, empower, facilitate, impact, improve, include, lead, organise, practice, produce, reflect, serve, study, sustain, transform, understand, value. These words reflect an action-oriented field.

It is the consistency and emphasis of these terms that leads to the development of the folksonomy, the vocabulary that is being produced from the tag clouds, that literally build a word picture of the profession. This folksonomy has been collectively produced by the various authors contributing to the written documents, and the tag clouds have extracted the key terms for easy viewing. It is apparent from the analysis of these documents that a folksonomy for home economics is likely to feature the terms identified in these two documents. A claim is being made in this analysis that there is evidence of a folksonomy of terminology used in the home economics field, however a more extensive analysis documents would need to be conducted to confirm this speculation. The question is whether this folksonomy is consistent with the values, goals and intentions of the profession.

The drilling down into the data to produce a tag cloud of gender related terms in the IFHE Congress Proceedings raises some concerns. In the tag cloud of the top 100 terms 'women' is the $63^{\text {rd }}$ most common term used, appearing 83 times in the proceedings. By contrast, the opposing term 'men' does not make the top 100 list, appearing only 35 times. As Table 3 reveals, it is almost twice as likely that a gender term from the range of feminine terms appears in the text compared to masculine terms. What message does this convey to the readers of the text/tag clouds? The field has argued over many years that it is not gender specific, yet the representational hierarchies indicate that the language of the artefacts is clearly gendered. 


\section{Summary and Conclusion}

This study has explored new territory for research which connects specifically with the multi-literacy capabilities of the Millennial generation. Similarities in the tag clouds produced from the analysed texts suggests a consistency in the relational aspects of many terms which appear in the documents. Evidence of frequently used proactive terms was abundant and this is a positive feature of this analysis. The high degree of consistency suggests there is a folksonomy emerging, even with the limited analysis conducted thus far. Of concern was the use of gendered terms which favoured feminine terminology.

It is recommended that tag clouds be included on the websites of IFHE and AAFCS as a constant update of the hierarchical text analysis and as a way of attracting the multiliterate capabilities for Millennials 'click and scanning' for information. As part of this study, tag clouds were developed for both websites, though it is beyond the scope of this paper to report the details of those tag clouds. Both the International Federation for Home Economics and the American Association for Family and Consumer Sciences highlighted generational understanding in their centennial conferences. This research adds to developing a greater understanding of how this might be achieved.

\section{Acknowledgements}

I wish to acknowledge the contributions made by Joy Reynolds as both research assistant and competent digital immigrant.

\section{References}

Arcus, M. (2008). 100 Years of the International Federation for Home Economics 19082008. Bonn: IFHE.

Eduation Queensland. (2009). Multiliteracies and communications media. Accessed 20 February 2009 http://education.qld.gov.au/corporate/newbasics/html/curric-org/comm.html

Halvey, M. \& Keane, M. (2007). An assessment of tag presentation techniques. Poster presented at the World Wide Web Conference May 8-12, 2007, Banff, Alberta, Canada. Accessed 20 February 2009 http://www2007.org/htmlposters/poster988/

Henderson, R. (2008). It's a digital life! Digital literacies, mulitliteracies and multimodality. Literacy Learning: The Middle Years, 16(2), 11-15.

International Federation for Home Economics. (2008). IFHE Position Statement - Home Economics in the $21^{\text {st }}$ Century. Bonn: IFHE. 
Oxford University Press. (2009). Facts about the Language.

Accessed 15 January 2009

http://www.askoxford.com/oec/mainpage/oec02/?view=uk

Pendergast, D. (2006). Sustaining the home economics profession in new times - A convergent moment. In: Rauma, A., Pollanen, S. \& Seitamaa-Hakkarainen, P. (Eds). Human Perspectives on Sustainable Future. Joensuu, Finland: University of Joensuu.

Pendergast, D. (2007). The MilGen and society. In: Bahr, N. \& Pendergast, D. The Millennial Adolescent. Canberra: Australian Council for Educational Research, 23-40.

Pendergast, D. (Ed.) (2008a). Home Economics: Reflecting the Past; Creating the Future. Proceedings of the IFHE XXI World Congress, July 26-31, Switzerland. Bonn: IFHE.

Pendergast, D. (2008b). Generational Dynamics - Y it matters 2 u \& me. In: Pendergast, D. (Ed). Home Economics: Reflecting the Past; Creating the Future. Bonn: IFHE, 99114.

Pendergast, D. (2008c). Introducing the IFHE Position Statement, International Journal of Home Economics, 1(1), 3-7.

Pendergast, D. (2009) Generational theory and home economics: Future proofing the profession. Family \& Consumer Sciences Research Journal, 37, in press.

Pink, D. (2005). Folksonomy. The New York Times Magazine, 11 December. Accessed 15 January 2009

http://www.nytimes.com/2005/12/11/magazine/11ideas1-21.html

Pinquart, M. \& Silbereisen, R. (2005). Social change and adolescent development at the beginning of the $21^{\text {st }}$ century. Journal of Research on Adolescence, 15(4), 395.

Prensky. M. (2005/6). Listen to the natives. Educational Leadership, 63 (4), 8-13.

Rennie, J. \& Patterson, A. (2008). Reading and identity: The google generation. Literacy and Learning: The Middle Years, 16(2), 53-58.

Salonen, J. (2007). Self-organising map based tag clouds - Creating spatially meaningful representations of tagging data. Proceedings of the 1st OPAALS Conference, 26-27 November, Rome, Italy

Accessed 15 January 2009

http://matriisi.ee.tut.fi/hypermedia/julkaisut/2007-salonen-som-clouds.pdf 